\title{
DE TRÁS-OS-MONTES AOS pampas uruguaios: os homens e seus (indissociáveis) arredores
}

Francisco Ferreira de Lima

Em literatura, ao contrário de muitos, sempre me interessaram mais as relaçôes do homem com o espaço do que com o tempo. Mas, infelizmente, não pude fazer grande avanço no campo dos estudos literários a partir dessa opçáo. Tirante dois ou três estudos de monta - um deles é o de Osman Lins acerca do espaço romanesco em Lima Barreto - , pelo menos no Brasil, o estudo do espaço em literatura, desde os manuais do ensino médio, reduzia-se a uma descrição monótona e enervante dos lugares percorridos pelas personagens, quase nunca sem estabelecer relação entre ambos, como se um fosse possível sem o outro.

A pobreza da investigação do espaço em literatura devia-se provavelmente ao peso que este ganhara nas teorias cientificistas do século XIX, pois, ao formularem a tríade, famosa, meio, momento e raça, o tornaram uma prisão, visto dele o homem jamais poder escapar. Habitando aquele determinado lugar, o homem estaria fatalisticamente marcado por ele por todos os séculos dos séculos, sem qualquer chance de escapar de suas determinaçôes. Ele seria o que o espaço - e seus outros dois fiéis companheiros, o meio e o momento - determinasse que fosse. Nasceu e viveu em área pobre, cercado de doença e marginalidade? Vai ser marginal, doente e pobre. E fim de papo. E o Naturalismo de segunda categoria, que o de primeira, como deve ser, fez literatura e náo ciência rasa, esforçou-se ao máximo para demonstrar a justeza da formulação. 
A partir do final do século passado, contudo, com a contribuição decisiva da geografia cultural, da fenomenologia e, embora menos, também da teoria da literatura, o quadro começou a mudar. E rapidamente. A desnaturalizaçáo do espaço, aí operada, jogou para a lato do lixo os últimos e renitentes apelos do espaço como natureza, para substituí-los pela ideia de construção, ou mais ainda, pela de invenção, como quer Anne Cauquelin (2007). A natureza, como a vemos, é paisagem, diz a autora. E paisagem é "uma invenção, um objeto cultural patenteado, cuja funçăo própria é reassegurar permanentemente os quadros da percepção do tempo e do espaço" (CAUQUELIN, 2007, p. 12). E já é assim pelo menos desde a invenção da perspectiva, que permitiu ao homem uma ampliação nos padrôes estéticos de observação do mundo.

Portanto, o que vemos da natureza, não é o que vemos da natureza, como já bem o sabia e dizia e tentou nos convencer Alberto Caeiro, senão um conjunto ordenado de "coisas paisagísticas, historicamente constituídas" (CAUQUELIN, 2007, p. 29). Coisas às quais re-naturalizamos para que fujam à condição de artifício, o que muito abalaria a relação homem-natureza. Tal processo, aliás, é fácil de perceber. E é ele, em última instância, que faz mover a indústria do turismo: para o nativo, tudo é natural; para o turista, tudo é novidade. Aquilo que enche os olhos deste, já não comove aquele, tamanha a naturalidade com que a paisagem se apresenta a seus olhos.

Mas que ninguém se engane. Toda paisagem é uma construção. E Duncan (2004, p. 109) diz melhor que eu:

Normalmente, as paisagens tendem a parecer naturais ou inevitáveis àqueles que vivem e trabalham nelas. Exceto sob circunstâncias excepcionais, a tangibilidade e a aparente transparência das características da paisagem tendem a convencer o observador local da paisagem de que as relaçóes sociais, políticas e econômicas permitidas pela sua organização são estabelecidas naturalmente, ou mesmo divinamente.

E acrescenta o geógrafo que basta a intromissão de um estranho a tal paisagem para desfamiliarizá-la, desvelando a ideologia transmitida por meio dela, dando a ver o que não se via ou o que não se era capaz de enxergar.

Nem natureza inocente nem cenário bucólico em que o homem passivamente se instala, a paisagem, diz o mesmo Duncan (2004, p. 106), é "um dos elementos centrais de um sistema cultural, pois, como um conjunto ordenado de objetos, um texto, age como um sistema de criação de signos, através do qual um sistema social é transmitido, reproduzido, experimentado e explorado".

E com tais e breves achegas, dou por estabelecidas as linhas teóricas com que vou ler os textos Repouso e Três homens, o primeiro do escritor português Miguel Torga e o 
segundo do uruguaio Mario Arregui, buscando estabelecer aproximaçóes na maneira como os autores tratam a paisagem e os homens nelas inseridos.

Em princípio, não parecem ter muito em comum escritores tão distanciados no espaço, um escrevendo sobre as gentes das montanhas ásperas e pedregosas de Trás-osMontes e o outro sobre os poucos seres humanos perdidos nas vastidóes dos pampas uruguaios. Mas é só em princípio, pois ambos põem suas personagens ante tarefa única e inadiável, a de decifrar o texto das paisagens que habitam, sem possibilidade de erro, pois, diante delas, como se dá com Sherazade, ler corretamente seus signos é a única maneira de manter-se vivo e livre, mesmo que isso implique a própria morte, como sucederá com o personagem de Torga. É isso que vou me esforçar para demonstrar.

Comecemos por Arregui.

Três homens é uma história de perseguição policial. E não poderia se iniciar de maneira melhor: "Era uma vez três homens" (ARREGUI, 1982, p. 37). Vou tratar de espaço e sou obrigado a começar pelo tratamento do tempo. Parece esquisito. Mas náo é, pois, nesse caso, tem tudo a ver. O "Era uma vez...", ao abolir referência precisa, como que dilui o tempo, fundindo-o no sem horizontes da paisagem. Homens perdidos no espaço, homens perdidos no tempo. Homens perdidos.

Após o ajuste espaço-temporal, vem a apresentação dos três homens. Eles são dados a conhecer pela ordem de importância que representam no sistema cultural. O primeiro é Ramiro Pazos, "comissário numa vasta área central de um dos departamentos centrais" (ARREGUI, 1982, p. 37). Trata-se da maior autoridade da região, já muito antigo no cargo, de reconhecida eficácia no trabalho, mas de personalidade extremada, pois, segundo o narrador, era dado a "atos de lúcida coragem e de violência mais ou menos arbitrária" (ARREGUI, 1982, p. 37), extremo que, logo se verá, desgraçará sua vida.

O segundo é o sargento Maciel, de acordo com o narrador, "homem baixo, de cara e sorriso que faziam amigos" (ARREGUI, 1982, p. 37). A informação do narrador acerca dos aspectos exteriores do sargento é de suma importância, pois reflete o que lhe vai no interior. $\mathrm{O}$ segundo lugar ocupado pelo sargento na ordem de apresentaçáo o coloca na posição de um planeta, rodeado por dois satélites. Tudo de importante na história passa pela decisão do sargento e não do comissário.

E, por fim, Bráulio Velasco, o perseguido, bandoleiro que inferniza a vida dos pagos e ali reaparece, alvo da cólera do comissário por ter sempre escapado de sua perseguição, não obstante sua condição de policial eficaz - eficácia já agora um tanto sob dúvida, uma vez que o leitor bem pode se perguntar: tanta eficácia e por que não já o prendeu?

Informado por estancieiros de que Velasco andava outra vez pelos arredores, Pazos decide sair imediatamente em sua perseguição, em companhia apenas do sargento 
Maciel. Acrescenta o narrador que o comissário faz saber ao sargento que a busca ao bandido dar-se-á em trajes civis. Tal informação adiciona um elemento fundamental à história, funcionando como boa parte da base para seu desfecho.

Embora o traje civil facilite a busca, ele implica, por outro lado, o apagamento das hierarquias, tão evidente na farda militar. Vestidos à civil, agora, são três homens iguais em sua condiçáo de humanidade, regidos por outras leis e outros poderes, coisa que o comissário só descobrirá tarde demais.

Três dias depois - e aqui o número de dias ganha significado especial, pois afirma a vastidão do lugar - ainda sem esperanças de encontrar o bandido, o comissário e o sargento preparam-se para pernoitar na estância de um inglês estranho, solitário e "quase misantropo", que vivia num casarão arruinado, cercado de cães de raça, e figura importante na narrativa para que se perceba melhor a personalidade do comissário, quando, não mais que de repente, avistam o bandoleiro na proximidade de um matagal, montado num "tordilho mui cabeceador".

Abra-se parêntese para acrescentar que foi o sargento Maciel a colher a informação de que Velasco andava montado nesse cavalo, informação fundamental, pois, diz o narrador, que "um homem a cavalo, visto de longe, é mais o cavalo do que o homem" (ARREGUI, 1982, p. 39). E o sargento Maciel só a obteve porque "sempre conseguia alguém com disposição de cooperar" (ARREGUI, 1982, p. 39), o que nos faz melhor conhecedores da capacidade do sargento de fazer amigos, enfim, do seu modo de ser, confiante e confiável.

Encurralado, sob uma saraivada de tiros, Velasco esconde-se no matagal. O sargento o segue de perto e ali também se embrenha. O comissário, que tinha desmontado para melhor fazer pontaria, retoma seu cavalo - "seu cavalo de confiança, o incansável e dócil zaino grande” (ARREGUI, 1982, 39), informa o narrador - e também parte para o mato. Tendo perdido os outros dois homens de vista, e dadas às difíceis condiçóes do matagal, o comissário desiste de procurá-los. Não por covardia, enfatiza o narrador, mas pelo infrutífero da busca, pois já anoitecia. De volta à boca da mata, o comissário espera pelo sargento Maciel por mais um tempo. Como este não aparece, decide dar continuidade ao plano que formulara antes do encontro com Velasco, o de dormir no rancho do inglês esquisito.

E ponha esquisito nisso. Mr. David Greenstreet recebe o comissário com desdém e soberba, servindo a cena, que funciona como um intervalo na história, para marcar confrontos culturais e identitários inarredáveis, mas também a pequenez do comissário. Decadente e misantropo, Mr. Greenstreet póe-se alheio às demandas deste, contrapondolhe à sua pequena e insignificante busca, que já não o interessa, sua participação no auge 
do período colonial inglês, quando caçou muitos homens. Agora nada importa; agora nada mais faz sentido, o que o leva a tratar o comissário como alguém insignificante, coisa que o deixa, diz o narrador, "mais desconcertado que ofendido", como a reconhecer e se colocar na posição de inferior.

Porém, apesar de sua arrogância, o inglês, embora se recuse a ir pessoalmente em busca de Velasco, pela insignificância da tarefa, pois agora, diz, os ingleses só caçam raposas, náo se incomoda que o comissário organize uma patrulha com seus peóes para ir em busca do facínora.

Mas já não era necessário. Maciel dera conta do recado. Velasco estava preso e bem amarrado. O comissário pode então transformar seu desconcerto em vingança, ao mandar um recado para o inglês, dizendo-lhe que os homens daquelas terras caçavam homens em vez de raposas.

E agora aproximamo-nos do final do conto e do que realmente interessa.

Ao ser perguntado como conseguiu tal proeza, o sargento Maciel, náo sem uma ponta de orgulho, diz que o conseguiu na peleja, na luta, o que fica visível nas marcas das feridas que leva no corpo e que minimiza como simples arranhôes.

Ao defrontar o bandoleiro, cuja "cara era tranquila e séria" (...) e "tinha os olhos semicerrados e como ausentes por completo" (ARREGUI, 1982, p. 44), o comissário fez vir à tona toda aquela violência extremada da qual já sabemos. Inicialmente a violência psicológica, pela humilhação do estado em que Velasco se encontrava, exagerando em seu sotaque espanhol para marcar bem a diferença - aquela mesma de que tinha sido vítima do inglês. Mas Velasco não se alterou. E sua reação merece ser apresentada.

Os olhos do bandoleiro continuavam cravados nos seus [do comissário, bem entendido]. Não viu neles temor, mas uma espécie de resistência primária, elementar, parecendo-lhe que duramente negavam-se, entre outras coisas, a vê-lo, a ver o senhor comissário Ramiro Passos, a ver nele algo mais do que um homem qualquer que the havia batido e que poderia bater de novo. (ARREGUI, 1982, p. 44)

Ante tanta indiferença, a fúria do comissário vai ganhando requintes de crueldade. Após um chute violento, sem que Velasco esboce reação, o sargento manifesta-se pela primeira vez, pedindo-lhe moderação. E pede-lhe mais uma e duas vezes, advertindo-o de que prendera o bandido na luta. E que se tal prática violenta continuar ele soltará Velasco. Mas o comissário, desvairado, só quer saber de brutalidade. O sargento, então, arrebata-lhe a arma, confronta-o, solta Velasco, entrega a este seu punhal, que o comissário já se apropriara do de Velasco e sai da clareira, sentando-se à margem de um arroio que por ali corria. Longos e intermináveis minutos depois, 
...ouviu passos surdos que se aproximavam, mas não se voltou [...] Continuou fitando a água e o reflexo mostrou-lhe que aquele homem era Velasco. Nem assim olhou para trás. Mais do que viu, sentiu a mão que lhe entregava a faca. Tomou-a, fitou-a, e a lavou, secando-a no cano da bota e restituindo-a à bainha que assomava do cinto.

— Às suas ordens, sargento - disse Velasco.

Maciel continuou imóvel e calado.

- Me entrego - insistiu o homem.

Maciel não olhou para o bandoleiro, nem para a imagem dele nas águas. Como para si mesmo, ou para ninguém, ou para o mutismo do lagoão ou para todos os homens, disse:

- O zaino do finado é mui guapo de patas.

(ARREGUI, 1982, p. 47)

Com certeza era para todos os homens que o sargento Maciel falava quando pronunciou sua frase derradeira, eivada de ironia, se pensarmos no amor que o comissário nutria por seu cavalo predileto. E o que ele diz, para além da frase, é que nos pagos, e sobretudo em trajes civis, um homem é só um homem, nada mais, nada menos que isso. E para sê-lo é preciso provar-se capaz. O conto finda-se, portanto, numa inversão da hierarquia inicial: Velasco, que mata na luta limpa e depois se entrega; o sargento, que vê em Velasco a humanidade, e o comissário, que, sem a força do poder e sem o poder $\mathrm{da}$ força, sucumbe ante as leis elementares desse mundo.

Não muito diferentes são os homens de Miguel Torga, perdidos nas serras pedregosas de Traz-os-Montes, vivendo naquelas paisagens inóspitas códigos de conduta ali arraigados por séculos, indiferentes às novidades do mundo,

Joaquim Lomba é um deles. Macambúzio da natureza, é o terror de Mondrôes. Com várias mortes nas costas, circula livremente pela aldeia, pois, diz o narrador, "com medo, ninguém queria fazer prova contra ele, e a justiça, diante do desinteresse de todos, desinteressava-se também" ( TORGA, 2009, p. 391).

Não se trata, porém, de um medo qualquer. Bandidos ainda mais violentos que Lomba já tinham circulado pela região, a exemplo de um certo Varela, que matara a mulher sentando-se sobre sua barriga. Mas com Lomba era diferente. Quando se falava dele, não era um medo qualquer que afetava as pessoas; era um "calafrio de pavor, diferente dos medos conhecidos", pois estampava, na ferocidade de seu rosto, a certeza de "mortes passadas e futuras".

E todo o problema se reduz - e disso resultará seu desfecho trágico - ao fato de que Lomba sabia dessa sua condição. E, mais importante ainda, lutava renhidamente contra ela, pois no avesso desse lado sinistro havia um outro, luminoso, em que "uma 
humanidade estuante, larga, generosa, queria mostrar-se à luz do sol" (TORGA, 2009, p. 392). Para sua desgraça, contudo, esse lado estava definitivamente contaminado pelo outro. E quando tentava exercê-lo, acabava por fazer bobagem - das grandes.

Como no dia em que matou Adriano, que teve a infelicidade de ser o primeiro a encontrá-lo em um dia feliz. Com vontade de abraçar a humanidade inteira, por estar se sentido um igual dela, Joaquim Lomba saúda efusivamente o pobre e apavorado Adriano, que, para livrar-se daquele medo desconhecido, responde-lhe de modo arredio. É o bastante para o coração de Lomba encher-se de ódio, só aplacado com a violência da morte, independentemente das tentativas de Adriano de se desculpar. Seu gesto medroso custou-lhe o tampo da cabeça, arrancado com sua própria roçadeira. Por essas e outras, conquanto se esforçasse para dar à luz a essa larga e generosa humanidade que carregava, Lomba só faz aumentar em torno de si a zona de calafrio de terror que provoca. E quanto mais essa zona se amplia, mais ele sofre.

Tenta, desesperado, a Igreja. Depois de confessar seus crimes, que o padre (e o mundo todo!) já conhecia, recusa-se a seguir a recomendação deste, de arrepender-se e pedir perdáo àqueles a quem desgraçou, pois nem se arrepende do que fez nem deseja pedir perdão a quem quer que seja. Ele só quer ser perdoado. E no mundo de Lomba, o representante de Deus na terra era autoridade suficiente para garantir-lhe o perdão, náo o fazendo por simples falta de vontade. Diante da negativa, a "amargura, a raiva e a negridão da vida se estamparam na cara dura e desgraçada do Lomba" (TORGA, 2009, p. 394).

Que, a partir daí, como que endoidou de vez. Nos festejos da Senhora da Boa Morte, ocorridos poucos meses depois da frustrada tentativa de confissão, Lomba, diz o narrador, "deu largas à sua angústia recalcada": fez parar a música no coreto, obrigando o maestro a trocar a polca que tocava por uma valsa, sob pena de arrancar-lhe os miolos com um tiro; fez o atirador de fogos disparar uma dúzia de morteiros antes do tempo previsto, sempre sob a ameaça da "grande e negra pistola; fez o charlatão de beberagens — "homem rijo e acostumado a zaragatas" - acabar com a conversa fiada do remédio que serve para tudo, arrumar seus frascos e "pensar na mulher e filhos"... Até deparar com um menino de nove anos que recolhia as canas - flechas, dizemos na Bahia - dos morteiros disparados.

E era tudo que Lomba precisava para resolver a vida, esse encontro. Chegando primeiro à cana, o menino a recolhe, com toda a energia, vitalidade e alegria de sua meninice. Chegando logo depois, já que, dentre outras, lhe faltavam essas três condiçôes, Lomba ordena ao menino que lhe entregue a cana. E o menino, na intensidade festiva de seus nove anos, responde-lhe com uma saraivada de desaforos, enfrentando-o 
de igual para igual como nunca antes acontecera, como nunca antes adulto algum se atrevera a fazer. E sai correndo em busca de outra cana, que outro morteiro já rasgava os céus e enchia de festa a noite de Mondróes, não sem antes perpetrar o desacato final, que é mandar um perplexo e estupefato Lomba ir lamber sabão.

Sua primeira reação, claro, que o gosto de sangue já estava na boca, é fazer o que sempre fez. Mas, logo em seguida, tal reação foi substituída, diz o narrador, por "um sorriso compassivo, terno, que lhe refrescou o coração" (TORGA, 2009, p. 395), que o faz sentir-se estranhamente feliz. Enquanto a festa espraia sons e cores cada vez mais intensos, o maestro com sua polca, os morteiros disparados na hora prevista, o vendedor de remédios apregoando milagres futuros, Lomba, afastando-se vagarosamente dali, mas finalmente em paz consigo mesmo, despeja a pistola no céu da boca, só sendo encontrado no fim da festa, e ali deixado, já que não há ninguém que dele se apiede, “à grande e pavorosa noite da montanha" (TORGA, 2009, p. 396).

Seja nas montanhas de Torga ou nos pagos de Arregui, seja Lomba ou Velasco, cumprem seus destinos, os únicos a serem cumpridos, porque inscritos nos códigos das paisagens, esses homens em seus indissociáveis arredores.

\section{$\operatorname{son} 2$}

\section{REFERÊNCIAS}

ARREGUI, Mario. Cavalos do amanhecer. Rio de Janeiro: Francisco Alves, 1982.

CAUQUELIN, ANNE. A invenção da paisagem. São Paulo: Martins Fontes, 2007.

COLLOT, Michel. Do horizonte da paisagem ao horizonte dos poetas. IN: ALVES, Ida Ferreira \& FEITOSA, Márcia Manir Miguel. Literatura e paisagem: perspectivas e diálogos. Rio de Janeiro: Editora da UFF, 2010.

DUNCAN, James. A paisagem como sistema de criação de signos. In: CORRÊA, Roberto Lobato \& ROSENDHAL, Zeni. Paisagens, textos e identidade. Rio de Janeiro: Eduerj, 2004.

TORGA, Miguel. Contos. 5.ed. Lisboa: D. Quixote, 2009.

\section{Resumo}

A paisagem, ensina Michel Collot, não é apenas um ponto de vista. O vê-la é só o ponto de partida para o vivê-la, para o habitá-la, o que resulta em verdadeiro exercício de poder. Tomada como extensão do eu, a paisagem, na sua habitação e vivência, autoriza a inscrição de todos os comportamentos possíveis e imagináveis naquilo que se dá a ver como totalidade recortada, pois agora o homem "é inseparável dos seus arredores". E, independente do modo que se apresenta, estejam onde estiverem seus horizontes, seja nas montanhas pedregosas de Trás-os-Montes de Miguel Torga ou no descampado do pampa uruguaio de Mario Arregui, a paisagem molda, modela e castiga seu 
vivente, ao tempo em que é moldada, modelada e castigada por ele, como se uma não fosse sem o outro. A partir dos conceitos de paisagem formulados pela mais recente geografia cultural, a comunicação investigará esse processo dialético de moldagem/modelagem entre homem e arredor e arredor e homem na leitura de um conto de cada um desses autores - Repouso, do primeiro, e Três homens, do segundo.

Palavras-chave: Conto; Paisagem; Identidade cultural.

\section{Abstract}

The landscape, teaches Michel Collot, is not only a point of view. It is only the starting point to live it, to inhabit it, which results in a true exercise of power. Taken as an extension of self, the landscape in its housing and living, authorizes the assumption of all possible and imaginable behaviors because now man "is inseparable from his surroundings". And, regardless of how it presents itself, Miguel Torga's stony mountains of Trás-os-Montes or Mario Arregui's Uruguayan pampa, the landscape models, shapes and punishes its inhabitant, and, at the same time, is molded, shaped and punished by him, as if one were not without the other. From the landscape concepts formulated by the most recent cultural geography, the paper investigates this dialectical process of shaping/modelling between man and surroundings and surroundings and man by means of the reading of a short story by each of these authors - Repouso by the former and Três homens by the latter.

Key words: Short story; Landscape; Cultural identity.

Francisco Ferreira de Lima é Professor Pleno de Literatura Portuguesa da UEFS. Graduado em Letras pela UFBA, Mestre pela PUC-RJ, Doutor pela USP e Pós-Doutor pela University of London - King's College. É autor de O outro livro das maravilhas: a Peregrinaçáo de Fernão Mendes Pinto (Rio de Janeiro: Relume Dumará, 1998); co-editor de A cor das letras e editor de Légua \& meia (UEFS). 